\title{
Refractive change in hyperglycaemia: hyperopia, not myopia
}

\author{
PAUL RIORDAN EVA, PATRICIA T. PASCOE, AND DANIEL G. VAUGHAN \\ From the Eye Medical Clinic of Santa Clara Valley, San Jose, California, 95126, USA
}

SUMMARY Sudden changes in refraction are a well recognised feature of hyperglycaemia. A tendency towards myopia has always been associated with elevations in blood glucose. Twelve diabetic patients were found to have experienced such refractive changes. Review of their records demonstrates that hyperglycaemia produces hyperopia. A theoretical mechanism for this phenomenon is discussed.

The occurrence of transitory refractive changes in diabetic patients has been recognised since $1873 .{ }^{1}$ However, since that initial observation there have been conflicting reports of the nature of the changes and the reasons for them.

After reviewing 3 of his own cases and 45 cases from the literature Duke-Elder in 1925 concluded that hyperopia is less common than myopia and that 'the refractive power of the eye tends to vary directly as the sugar content of the blood; that is, there is a tendency to hypermetropia with decreased sugar, with increased sugar to myopia.' ${ }^{2}$ Both Bellows and Roberts agreed with this association but maintained that diabetic myopia is less common than diabetic hyperopia. ${ }^{34}$ Granström reported refractive change occurring as an initial symptom in $34 \%$ of diabetics and as an asymptomatic change in another $47 \% .^{5}$

It has been said that hyperopia seems not to occur as an initial phenomenon in diabetes but to follow myopic change, ${ }^{6}$ and many authors have correlated the development of hyperopia-or the reversal of myopia-with a falling blood sugar, usually associated with treatment of hyperglycaemia and especially if this is rapid. ${ }^{24-12}$ It has also been suggested that hyperopic change in diabetes occurs almost exclusively in those patients receiving insulin. ${ }^{13}$

In 1956 there was a report by Rosen of a single case of hyperopia due to hyperglycaemia. ${ }^{14}$ More recently Duke-Elder's rule has been refuted by Planten's study of 23 patients of whom only 2 became myopic with hyperglycaemia, the remainder all showing transient hyperopia. ${ }^{15}$ Feinblum presented 100 cases in which the initial diagnosis of diabetes was based on

Correspondence to P. Riordan Eva, c/o Medical Eye Unit, St Thomas's Hospital, Lambeth Palace Road, London SE1 7EH. a sudden refractive change, hyperglycaemia always being associated with hyperopia. ${ }^{16}$

Most authors accept Duke-Elder's theory that refractive changes in diabetes are due to alterations in the power of the lens because of osmotic interactions between the lens and aqueous. ${ }^{2367101718}$ Myopia with hyperglycaemia was then explained as being due to osmotic hydration of the lens due to salt retention. ${ }^{23}$ Rosen accounted for hyperopia with hyperglycaemia by assuming that hydration must involve the nucleus as well. ${ }^{14}$ Meanwhile Granström suggested that the hydration would occur when the blood sugar was decreased, and that involvement of the nucleus preferentially would account for the hyperopia developing at that time. ${ }^{5}$

Later writers have suggested that intralenticular osmotic pressure increases during hyperglycaemia as glucose and its metabolic products, especially those derived from the sorbitol pathway, accumulate within the lens. ${ }^{7131920}$ The resultant influx of water has been used to explain either a myopic or a hyperopic change, according to whether shape or refractive index is considered more important in determining overall refractive power. ${ }^{19-21}$

For this paper we have reviewed the records of all of the diabetics seen by D.G.V. in his clinic from 1959 to 1981 who are known to have had a sudden visual change in association with hyperglycaemia. Thirteen such instances in 12 diabetic patients are reported. Every case showed transient hyperopia developing prior to the diagnosis of diabetes or soon after treatment was started, or in some cases at the time of an acute disturbance in the course of their disease. There was no evidence of any association between hyperglycaemia and myopia. A possible mechanism 
for the development of hyperopia involving the sorbitol pathway of metabolism is discussed.

\section{Case reports}

\section{GROUP A}

Patient 1, a 65-year-old woman, was admitted to hospital on 11 September 1973 with a 4-week history of weight loss, thirst, vaginitis, and weakness. She had also had blurring of vision, both near and distance, for one week. She was diagnosed as having diabetes. After control had been established she was discharged from hospital on insulin therapy.

She was seen in the clinic on 12 October, at which time her vision was still blurred. There had been no apparent improvement in her visual status. Visual acuity was 20/200(6/60) in each eye with her current prescription $(\mathrm{OD}+1 \cdot 50=+1 \cdot 00 \times 20$, OS $+1 \cdot 50=$ $+0 \cdot 50 \times 155$ ). Best corrected visual acuity was $20 / 20$ (6/6) with OD $+3 \cdot 25=+1 \cdot 00 \times 20$, OS $+3 \cdot 75=+0 \cdot 50$ $\times 155$. Temporary $+1 \cdot 50$ clips were recommended.

Within 5 weeks of this examination the right eye had returned to its previous refractive error of $+1 \cdot 50$, but the left only settled to $+1 \cdot 75$ after another 5 weeks.

Four other cases (patients 2-5) were seen in which the appearance of hyperopic refractive changes predated the diagnosis of diabetes. In 2 of these it is definitely known that hyperopia also preceded the development of other diabetic symptoms.

\section{GROUP B}

Patient 6, a 35-year-old woman, was seen in hospital on 18 May 1967 at the request of her internist. She had been admitted on 8 May for stabilisation of recently diagnosed diabetes mellitus. There was a history of polyuria, polydipsia, fatigue, and vaginal pruritus, and she had been initially treated for 3 days with tolbutamide. Because oral therapy failed to control the blood sugar, which was $440 \mathrm{mg} / \mathrm{dl}(24$ $\mathrm{mmol} / \mathrm{l})$ on the day of admission insulin therapy was instituted at that time.

The patient had had no visual symptoms until the day after her admission, when she noticed blurring of near vision progressing to involve distance vision 4 days later. Her vision remained the same until after the initial consultation, but meanwhile she noticed that she could see much better, both near and distance, with some $+2 \cdot 50$ cheap reading glasses. Her normal prescription was $-0.50=+0 \cdot 50 \times 90 \mathrm{OU}$.

Examination at the time of the initial consultation revealed an uncorrected visual acuity of approximately $20 / 200(6 / 60)$ in each eye, corrected to approximately $20 / 40(6 / 12)$ with the reading glasses. At a more formal examination on 29 May, after her discharge, the patient said that her vision had started to improve 4 days previously, so that she was no longer able to see at a distance with the $+2 \cdot 50$ reading glasses and she could read without glasses. Refraction then disclosed a +1.25 error in each eye with corrected visual acuity of OD $20 / 25(6 / 7 \cdot 5)$ and OS $20 / 30(6 / 9)$. Further improvement did occur, and the refractive error settled at +0.25 in the right eye and +0.50 in the left by November 1967 .

Patient 7, a 64-year-old man, was being followed up at the clinic after a retinal detachment in 1955 . The last refraction before the onset of diabetes was in June 1980, when corrected visual acuity was 20/30 (6/9) with $-4 \cdot 75=+1.00 \times 170$ in the right eye and $-4 \cdot 75=+1 \cdot 00 \times 30$ in the left.

In December 1980 he suddenly developed severe polydipsia and polyuria. On 15 December investigation by his internist showed a full blood sugar value of $350 \mathrm{mg} / \mathrm{dl}(19 \mathrm{mmol} / \mathrm{l})$. Chlorpropamide, one tablet per day, was started. Although the patient discontinued this treatment within a few days because of side effects, frequent blood sugar estimations continued to show improvement.

About 2 weeks after initiation of treatment the patient noticed a sudden change in his vision in that he could no longer see street signs while driving unless he took his glasses off. Examination by an optometrist on 8 January 1981 showed best visual acuity of $20 / 25$ $(6 / 7 \cdot 5)$ with corrections of -1.75 in each eye. Referral back to an ophthalmologist was advised. The patient's prediabetic refractive error was found to have returned on 27 February 1981.

One other patient (patient 8) gave a similar history of suddenly being able to see in the distance without glasses, despite previously being myopic, about 2 weeks after starting oral medication for newly diagnosed diabetes.

\section{GROUP C}

Patient 9, a 36-year-old diabetic woman had been taking chlorpropamide for 5 years when she developed influenza in January 1972, and her diabetes went out of control. By 8 February her full blood sugar had risen to $350 \mathrm{mg} / \mathrm{dl}(19 \mathrm{mmol} / \mathrm{l})$ and she was advised to start insulin therapy on 19 February. Until that time she had had no visual symptoms since the onset of her diabetes in 1967 , but within 3 hours of the first injection of 10 units of regular insulin she noticed blurring of vision in both eyes. She could not see with her glasses (OD $-3 \cdot 25=$ $+0 \cdot 25 \times 135$, OS $-3 \cdot 75=+1 \cdot 25 \times 40$ ), but she could see near without them. A formal refraction on 22 February showed visual acuity of 20/200 (6/60) OU with her present glasses, OD 20/80 (6/24) and OS $20 / 60(6 / 18)$ without correction, and $20 / 20(6 / 6)$ with a -1.50 sphere in each eye. Temporary +1.50 were recommended. 
An increase in the dosage of insulin led to gradual lowering of the blood sugar, followed later by a reversal of the refractive change. In January 1973 the refractive errors had returned to -3.25 in the right eye and -3.50 in the left with the same astigmatic corrections.

Three other patients (patients 10-12) were recorded as experiencing hyperopic refractive changes in association with exacerbations of diabetes already under treatment. Patient 11 had two similar episodes in the space of $2 \frac{1 / 2}{2}$ years. In all cases the disturbance of vision occurred soon after treatment was'altered to control hyperglycaemia.

In Table 1 are listed the actual values of the refractions for each patient before the hyperglycaemic episode and at the time of the maximum measured change. All refractions were carried out by D.G.V. There was no apparent effect on the astigmatic corrections, and so these are not shown. The peak blood sugar value is also recorded in each case, but it is not possible to make any valid correlation between this and the measured refractive changes because of differences in the timing of these measurements.

\section{Discussion}

Although many textbooks of ophthalmology discuss temporary refractive changes as a feature of diabetes mellitus, the nature of such changes has not been defined. Most authors still adhere to Duke-Elder's concept of myopia associated with hyperglycaemia, and only a few report the possibility of hyperopia under such circumstances. ${ }^{17} 2223$

This paper presents 13 instances in which hyperglycaemia produced either hyperopia or a reversal of myopia. Our cases failed to support the view that elevations of blood glucose in diabetes are accompanied by a tendency towards myopia. The patients' own accounts of their visual changes as well as objective evidence obtained by clinical refraction directly contradict that opinion. Other recent publications lend support to our finding, ${ }^{1516}$ but the series reported here is the first in the ophthalmological literature that demonstrates an association between hyperglycaemia and hyperopia in a substantial number of well-studied cases.

In this series the age range of cases is from 27 to 72 years, with most of the patients over 50 . Although

Table 1 Hyperglycaemia-induced hyperopia in 12 diabetic patients

\begin{tabular}{|c|c|c|c|c|c|c|}
\hline \multirow[t]{2}{*}{ Patient } & \multirow[t]{2}{*}{ Age } & \multirow[t]{2}{*}{$\operatorname{Sex}$} & \multicolumn{2}{|l|}{ Refractions } & \multirow{2}{*}{$\begin{array}{l}\text { Overall refractive } \\
\text { change }\end{array}$} & \multirow{2}{*}{$\begin{array}{l}\text { Peak full blood } \\
\text { sugar mg/dl }\end{array}$} \\
\hline & & & Before hyperglycaemia & Maximum change & & \\
\hline \multicolumn{7}{|c|}{ Group A: Prior to diagnosis } \\
\hline 1 & 65 & $\mathbf{F}$ & $\begin{array}{l}\text { OD }+1 \cdot 50 \\
O S+1 \cdot 50\end{array}$ & $\begin{array}{l}+3 \cdot 25 \\
+3 \cdot 75\end{array}$ & $\begin{array}{l}+1 \cdot 75 \\
+2 \cdot 25\end{array}$ & 550 \\
\hline 2 & 57 & $\mathrm{~F}$ & $\begin{array}{l}\text { OD }+2 \cdot 50 \\
O S+2 \cdot 00\end{array}$ & $\begin{array}{l}+3 \cdot 25 \\
+3 \cdot 00\end{array}$ & $\begin{array}{l}+0 \cdot 75 \\
+1.00\end{array}$ & 315 \\
\hline 3 & 63 & $\mathbf{M}$ & $\begin{array}{l}\text { OD }-0.75 \\
\text { OS }-3.50\end{array}$ & $\begin{array}{l}+0 \cdot 50 \\
-0.50\end{array}$ & $\begin{array}{l}+1 \cdot 25 \\
+3 \cdot 00\end{array}$ & 360 \\
\hline 4 & 72 & $\mathrm{~F}$ & $\begin{array}{l}\text { OD Plano } \\
\text { OS Plano }\end{array}$ & $\begin{array}{l}+1.75 \\
+1.25\end{array}$ & $\begin{array}{l}+1 \cdot 75 \\
+1 \cdot 25\end{array}$ & 300 \\
\hline 5 & 27 & $\mathrm{~F}$ & $\begin{array}{l}\text { OD }-0 \cdot 25 \\
\text { OS Plano }\end{array}$ & $\begin{array}{l}\text { NA } \\
\text { NA }\end{array}$ & $\begin{array}{l}\text { NA } \\
\text { NA }\end{array}$ & 560 \\
\hline \multicolumn{7}{|c|}{ Group B: Soon after treatment } \\
\hline 6 & 35 & $\mathbf{F}$ & $\begin{array}{l}\text { OD }-0.50 \\
\text { OS }-0.50\end{array}$ & $\begin{array}{l}+1 \cdot 25 \\
+1 \cdot 25\end{array}$ & $\begin{array}{l}+1.75 \\
+1.75\end{array}$ & 440 \\
\hline 7 & 64 & $\mathbf{M}$ & $\begin{array}{l}\text { OD }-4 \cdot 75 \\
\text { OS }-4 \cdot 75\end{array}$ & $\begin{array}{l}-1.75 \\
-1.75\end{array}$ & $\begin{array}{l}+3 \cdot 00 \\
+3 \cdot 00\end{array}$ & 350 \\
\hline 8 & 63 & $\mathbf{M}$ & $\begin{array}{l}\text { OD }-3 \cdot 50 \\
\text { OS }-3 \cdot 00\end{array}$ & $\begin{array}{l}-1.00 \\
-0.50\end{array}$ & $\begin{array}{l}+2 \cdot 50 \\
+2 \cdot 50\end{array}$ & NA \\
\hline \multicolumn{7}{|c|}{ Group C: Previously treated diabetes } \\
\hline 9 & 36 & $\mathbf{F}$ & $\begin{array}{l}\text { OD }-3 \cdot 25 \\
\text { OS }-3 \cdot 75\end{array}$ & $\begin{array}{l}-1 \cdot 50 \\
-1 \cdot 50\end{array}$ & $\begin{array}{l}+1 \cdot 75 \\
+2 \cdot 25\end{array}$ & 350 \\
\hline 10 & 62 & $\mathbf{F}$ & $\begin{array}{l}\text { OD }+1: 25 \\
O S+1 \cdot 50\end{array}$ & $\begin{array}{l}+3 \cdot 00 \\
+3 \cdot 00\end{array}$ & $\begin{array}{l}+1 \cdot 75 \\
+1.50\end{array}$ & 345 \\
\hline 11 (i) & 52 & $\mathrm{~F}$ & $\begin{array}{l}\text { OD }-1 \cdot 00 \\
\text { OS }-2 \cdot 00\end{array}$ & $\begin{array}{l}+1 \cdot 50 \\
+1 \cdot 25\end{array}$ & $\begin{array}{l}+2 \cdot 50 \\
+3 \cdot 25\end{array}$ & 448 \\
\hline 11 (ii) & 54 & $\mathbf{F}$ & $\begin{array}{l}\text { OD }-0.75 \\
\text { OS }-1.50\end{array}$ & $\begin{array}{l}+1 \cdot 50 \\
+1 \cdot 50\end{array}$ & $\begin{array}{l}+2 \cdot 25 \\
+3 \cdot 00\end{array}$ & 576 \\
\hline 12 & 65 & $\mathbf{F}$ & $\begin{array}{l}\text { OD }+1 \cdot 25 \\
\text { OS }+1 \cdot 25\end{array}$ & $\begin{array}{l}+3 \cdot 75 \\
+3 \cdot 50\end{array}$ & $\begin{array}{l}+2 \cdot 50 \\
+2 \cdot 25\end{array}$ & 318 \\
\hline
\end{tabular}

$\mathrm{NA}=$ not available.

SI conversion $=\mathrm{mg} / \mathrm{dl} \times 0 \cdot 0555=\mathrm{mmol} / \mathrm{l}$. 
this does not establish an association with advancing years, it does show that this effect is not necessarily confined to younger diabetics, as claimed by Himsworth. ${ }^{24}$ Furthermore of the cases presenting with visual changes near the time of the initial diagnosis of diabetes 4 were treated with insulin and 4 with oral medication. There was a good correlation between the peak full blood sugar value and the treatment method used. Thus it would seem that hyperopia is not necessarily commoner in patients who have severe metabolic disturbance at the onset, or those treated with insulin.

The development of refractive abnormalities in response to hyperglycaemia is characterised by rapid onset followed by prolonged regression. ${ }^{271113}$ In all our cases the hyperopic change occurred suddenly, never taking more than a few hours to appear. Return to the previous refractive state often required weeks, depending on how rapidly and reliably the blood glucose level was controlled. Patients adequately treated with insulin improved steadily over a period of 6 to 10 weeks, whereas those receiving oral medication took as long as 20 weeks. In one case (patient 9) a year elapsed before suitable refraction was re-established, probably due in large part to failure to achieve satisfactory diabetic control. Previous investigators have generally believed refractive changes in diabetes, whether they be myopic or hyperopic, to be completely reversible. Two of our 12 cases (patients 4 and 6) failed to return to within one dioptre of their prediabetic refraction in either eye even with well-documented satisfactory control of diabetes. It has been suggested that this phenomenon may be due to reliance on quantitative urine analysis, in patients with high renal thresholds, rather than regular monitoring of blood glucose. ${ }^{16}$ However, it is known that-at least in the case of patient 4-frequent blood glucose examinations were being done.

The magnitude of the measured refractive changes in this series ranges from 0.75 to 3.25 dioptres. Although these may be underestimates because of delay between the onset of the refractive change and the time of the next formal refraction, including when subjective visual improvement had been noticed, the results are the same as those given by other authors. ${ }^{611} 1214-16$ In all cases both eyes were affected, and in only one instance (patient 3) was there a difference of more than 0.75 dioptres between the changes in the 2 eyes. This may have been related to the great disparity in this patient's prediabetic refraction. The sex distribution in this study shows a bias (3:1) towards women.

As has been mentioned, several mechanisms have been proposed to explain temporary abnormalities of refraction in diabetes, often with only apparently minor differences according to the nature of the changes observed. Duke-Elder in 1925 extensively reviewed the ideas current at that time and set forth the 2 concepts of a lenticular origin and an osmotic basis for this phenomenon. ${ }^{2} \mathrm{He}$ listed 6 major reasons for implicating the lens, of which Elschnig's observations in unilateral aphakia are the most persuasive, and provided an elaborate exposition of the possible role of osmotic forces, which established the concept without truly explaining the mechanism. His idea of a decrease in the osmotic pressure of the aqueous in the face of hyperglycaemia, with consequent hydration of the cortical layers of the lens, has been reiterated by other authors. However, recent physiological evidence is to the contrary (see below). Caird, Pirie, and Ramsell in $1969^{13}$ suggested that the osmotically active substances involved may actually be formed within the lens, and this theory has subsequently attracted a number of supporters. ${ }^{719} 2025$

By 1965 it had been reported that the sorbitol pathway is active in the lenses of both humans and animals and that in diabetes the metabolites of the pathway are abnormally high. ${ }^{26-29}$ Incrimination of polyol production in the development of cataracts in galactosaemia led to an intensive search for a similar mechanism in diabetic cataracts. ${ }^{30-32}$ Furthermore, since it is known that the metabolites can accumulate to significant levels within a few hours, similar mechanisms have been considered as the basis of more acute changes in the lens. ${ }^{25}{ }^{33}$ It is known that there is a direct correlation between the level of glucose in the aqueous and that in the blood under normal or hyperglycaemic conditions. ${ }^{34}$ However, the corresponding relationship between the lens and the aqueous is more complex.

Experimental data suggest that glucose diffuses into the lens and permeates the small extracellular space, which accounts for $5-10 \%$ of the lens volume, and that at normal levels of glucose in the blood and aqueous humour the rate of glucose utilisation by the lens fibre cells is equal to its rate of entry, so that the cells are essentially glucose-free. ${ }^{3435}$ However, if glucose levels in the surrounding medium are increased, lens fibres seem to accumulate glucose, and more especially-because of the apparent diversion of this substrate into the sorbitol pathwaythe metabolites sorbitol and fructose. ${ }^{36}$ The reason is probably saturation of the enzyme hexokinase, the starting point of the glycolytic and pentose phosphate pathways in combination with the markedly higher $\mathrm{Km}$ of aldose reductase, the first enzyme of the sorbitol pathway. ${ }^{37}$ The net result is an accumulation of fructose and sorbitol, both of which penetrate lens membranes poorly and are further metabolised to only a limited extent. Since their concentrations may not be matched in the aqueous humour, an osmotic 
imbalance may develop, with the consequent imbibition of water. Experiments with human lenses have shown that lens tissue is capable of forming sufficiently high levels of sorbitol with 24 hours of continuous hyperglycaemia, to lead to a hypertonic state. ${ }^{37}$ Hyperglycaemia-induced refractive changes have been prevented in rabbits by aldose reductase inhibitors, although similar work in human subjects has yet to be published. ${ }^{25} 33$

There has been much debate about which part of the lens is responsible for the refractive changes during hyperglycaemia. Since reliance still must be placed on models to explain the physiological optics of the lens, and since little is known about the applicability of such studies to lenticular function under pathological conditions, it is difficult to choose among the proposed hypotheses. Studies involving direct examination of human lenses in vivo during hyperglycaemia are scarce. Huggert observed 'blurring of the inner surface of the lens' on slit-lamp examination in patients with transitory diabetic hyperopia and suggested that there may have been some swelling anterior to the nucleus. ${ }^{38}$ More rapid changes were observed by Vere and Verel, who ascribed dimming of the red reflex with hyperglycaemia to transient opacity in the anterior lens. ${ }^{39}$ They discounted hyperopic change as a possible alternative cause-although shown to have a similar effect-because of Duke-Elder's association of hyperglycaemia with myopia. Following up their personal studies published in 1975, Planten et al., with the aid of ultrasonic A scans, failed to reveal any difference in the optic parameters of the lens and its position in the eye during and after episodes of hyperopia in diabetes. ${ }^{21}$ Their conclusion, supported by mathematical evidence of its feasibility, was that changes of the refractive indices in the various layers of the lens are the cause of the hyperopia developing in diabetes, rather than an alteration in the size of the lens. Subsequently they showed that such changes can be visualised by the appearance of refractive surfaces in the lenticular cortex. ${ }^{40}$ It would thus appear that a decrease in the refractive indices within the anterior portions of the lens might produce the hyperopia associated with hyperglycaemia. It is tempting to speculate that an osmotic effect due to the accumulation of sorbitol and fructose could account for these findings, since aldose reductase is known to be principally located in the lens epithelium and cortex. ${ }^{37}$

Before accepting a theory it is necessary not only to prove its own merit but also to explain why other theories are either wrong or not applicable. A review of the published series shows that many writers on this subject had no knowledge of their subjects' refractive error before the onset of hyperglycaemia and that many analysed the refractive changes only after treatment had been started. It is of interest that a number of our cases show a relationship with the onset of treatment and not necessarily with the development of hyperglycaemia per se. Hyperopic change occurs in these instances as a possible consequence of the reduction of the blood sugar after a period of hyperglycaemia. Analysis of the first case cited in Duke-Elder's original paper shows an identical happening. Duke-Elder was also able to demonstrate that subsequent elevation of blood glucose resulted in a reversal of this change, causing only slight myopia-in comparison with the patient's subsequently established normal refraction-when the blood sugar was grossly elevated. The findings convinced Duke-Elder that there must be a direct association between myopia and hyperglycaemia, but it would appear more likely that there is some link between hyperglycaemia and hyperopia, which is modulated by the prevailing blood glucose level. It is logical to assume that, if the change in refraction depends on an osmotic force acting from within the lens, then any osmotically active substance-such as glucose-in high concentration in the aqueous may be able to counteract this force. Imbibition of water into the lens could then not occur until the extralenticular glucose concentration had been reduced. Thus a balance can be visualised between the amount of accumulated sorbitol or fructose and the extralenticular glucose concentration that controls the movement of water into and out of the lens. A grossly elevated glucose level may produce rapid accumulation of polyol metabolites, but these cannot exert any osmotic effect without a reduction in the sugar level; whereas in the presence of a relatively small elevation of glucose over a longer period of time a sufficient accumulation of metabolites may have an overall osmotic effect. Alloxan-induced diabetes in animals has been noted to produce refractive changes, which are always hyperopic even in the presence of elevated blood glucose. ${ }^{13}$ This fact may be related to the much greater activity of the enzymes of the sorbitol pathway in the lenses of such animals. ${ }^{37}$

Further extrapolation of this mechanism suggests that the few instances in which myopia does occur, with severe metabolic disturbance, would be due to an osmotic dehydration of the lens because of rapid elevation in extralenticular glucose in advance of the accumulation of polyol metabolites. This would then be short-lived, hyperopia developing once the metabolites have accumulated and the extralenticular glucose level has been reduced.

Whether an increase in the metabolism of glucose via the sorbitol pathway with consequent accumulation of polyol metabolites does account for the refractive changes produced by hyperglycaemia is not 
conclusively established. Such a mechanism does provide an explanation for many of the features of these refractive changes, especially their time of onset and regression. Furthermore it would establish a direct link with current ideas concerning cataractogenesis in diabetes. The most important result of the study offered here, however, is that hyperopia is the refractive change associated with hyperglycaemia.

We are grateful to James Ransom, $\mathrm{PhD}$, for his editorial advice and John H. Sullivan, MD, for his help in compiling this paper. Nancy Kettman kindly typed the manuscript.

Paul Riordan Eva was a student-fellow of the Francis I. Proctor Foundation for Research in Ophthalmology, University of California, San Francisco. Support for this study was provided by the Sight Conservation Research Center, San Jose, and the Alta California Research Foundation, San Francisco.

\section{References}

1 Horner JF. Quoted by Duke-Elder S. System of Ophthalmology. London: Kimpton, 1970: 5.

2 Duke-Elder S. Changes in refraction in diabetes mellitus. $\mathrm{Br} J$ Ophthalmol 1925; 9: 167-87.

3 Bellows JG. The crystalline lens in diabetes mellitus. Arch Ophthalmol 1944; 32: 498-507.

4 Roberts W. Rapid lens changes in diabetes mellitus. Am J Ophthalmol 1951; 33: 1283-5.

5 Granström KO. Refraktionsveranderungen bei diabetes mellitus. Acta Ophthalmol (Kbh) 1933; 11: 1-161.

6 Duke-Elder S. System of Ophthalmology. London: Kimpton, 1970: 5: 368-70.

7 Brooks MH. Lenticular abnormalities in endocrine dysfunction. In: Bellows JG, ed. Cataract and Abnormalities of the Lens. St Louis: Mosby, 1975: 285-6.

8 Henkind P. The eye in diabetes mellitus: signs, symptoms and pathogenesis. In: Mausolf FA, ed. The Eye and Systemic Disease. St Louis: Mosby, 1980: 196.

9 Scheie HG, Albert DM. Textbook of Ophthalmology. Philadelphia: Saunders, 1977: 438.

10 Miller SJ. Parson's Diseases of the Eye. London: ChurchillLivingstone, 1978: 576.

11 Pyke DA. The eye in diabetes. In: Rose FC, ed. Medical Ophthalmology. London: Chapman and Hall, 1976: 437.

12 Rodger FC, Sinclair HM. Metabolic and Nutritional Eye Diseases. Springfield: Thomas, 1969: 77.

13 Caird FI, Pirie A, Ramsell TG. Diabetes and the Eye. Oxford: Blackwell, 1969: 122-6.

14 Rosen M. Diabetes mellitus with relative hyperopia. Am J Ophthalmol 1956; 41: 680-1.

15 Planten J Th. Physiologic optic approach of lens and cataract. Ophthalmologica 1975; 171: 249-53.

16 Feinblum SM. Clinical significance of refractive changes in diabetes. Optometric Weekly 1972: 63: 199-206.

17 Sorsby A. Modern Ophthalmology. Philadelphia: Lippincott, 1972: 3: 33 .

18 Abrams D. Duke-Elder's Practice of Refraction. London: Churchill-Livingstone, 1978: 59.
19 Moses RA. Alder's Physiology of the Eye: Clinical Applications. St Louis: Mosby, 1981: 296.

20 Keller JT. A mechanism for refractive changes in diabetes. Am J Optom Physiol Opt 1973: 50: 108-11.

21 Planten JT, Kooijman AC, de Vries B, Woldringh JJH. Pathological-optic approach of cataract and lens. Ophthalmologica 1978; 176: 331-4.

22 Kaufman HE, Copenhaver RM. Eye manifestations of inborn metabolic errors and systemic disease. In: Holt LB, ed. Pediatric Ophthalmology. Philadelphia: Lea and Febiger, 1964: 36.

23 Vaughan D, Asbury T. General Ophthalmology. California: Lange, 1980: 333

24 Himsworth HP. Temporary visual disturbance as an initial symptom of diabetes mellitus. Br Med J 1931; H: 1184-6.

25 Chylack LT Jr. Sugar cataracts: possibly the beginning of medical anti-cataract therapy. In: Duncan G, ed. Mechanisms of Cataract Formation in the Human Lens. London: Academic Press, 1981: 237-52.

26 van Heyningen $R$. The sorbitol pathway in the lens. Exp Eye Res 1962; 1: 396-404.

27 Pirie A, van Heyningen R. The effect of diabetes on the content of sorbitol, glucose, fructose and inositol in the human lens. Exp Eye Res 1964; 3: 124-31.

28 Kinsey VE, Wachtl C, Kuck JFR Jr, Reddy DVN. Current research on the culture of lenses. Acta XVIII Cong Ophthal Belgium (1958) 1959; 1: 865-72.

29 Kuck JRF Jr. The formation of fructose in the ocular lens. Arch Ophthalmol 1961; 65: 840-6.

30 Kinoshita JH, Merola LO, Satoh K, Dikmak E. Osmotic changes caused by the accumulation of dulcitol in the lenses of rats fed with galactose. Nature 1962; 194: 1085-7.

31 Kinoshita JH, Merola LO. Hydration of the lens during the development of galactose cataract. Invest Ophthalmol Visual Sci 1964; 3: 577-84.

32 Chylack LT Jr, Kinoshita JH. A biochemical evaluation of a cataract induced in a high glucose medium. Invest Ophthalmol Visual Sci 1969; 8: 401-12.

33 Varma SD, El-Aguizy HK, Richards RD. Refractive change in alloxan diabetic rabbits-control by flavonoids I. Acta Ophthalmol (Kbh) 1980; 58: 748-59.

34 Caird FI, Pirie A, Ramsell TG. Diabetes and the Eye. Oxford: Blackwell, 1969: 143-4.

35 Patterson JW. A review of glucose transport in the lens. Invest Ophthalmol Visual Sci 1965; 4: 667-79.

36 Varma SD, Schocket SS, Richards RD. Implications of aldose reductase in cataracts in human diabetes. Invest Ophthalmol Visual Sci 1979; 18: 237-41.

37 Jedziniak JA, Chylack LT Jr, Cheng H-M, Gillis MK, Kalustian AA, Tung WH. The sorbitol pathway in the human lens: aldose reductase and polyol dehydrogenase. Invest Ophthalmol Visual Sci 1981; 20: 314-26.

38 Huggert $A$. The appearance of the crystalline lens during different stages of transitory changes of refraction. Part II. Acta Ophthalmol (Kbh) 1954; 32: 375-89.

39 Vere DW, Verel D. Relation between blood sugar level and the optical properties of the lens of the human eye. Clin Sci 1955; 14: 183-96.

40 Planten J Th. Changes of refraction in the adult eye due to changing refractive indices of the layers of the lens. Ophthalmologica 1981; 183: 86-90. 